한국심리학회지: 산업 및 조직

Korean Journal of Industrial and Organizational Psychology

2013. Vol. 26, No. 2, 219-243

\title{
Temporal Dynamics of Emotions Within a Workday: The Moderating Effect of Neuroticism*
}

\author{
Jae Yoon Chang ${ }^{\dagger}$ \\ Sogang University
}

\author{
Allison L. Cook
}

Texas A\&M University

\author{
Stephanie C. Payne
}

\begin{abstract}
The purpose of this study was to examine how positive and negative emotions fluctuate over time within one workday and to investigate the moderating effects of neuroticism and job satisfaction. Data were obtained from 201 Seoul citizens in Korea using the Day Reconstruction Method (Kahneman, Krueger, Schkade, Schwarz, \& Stone, 2004). Data revealed that negative emotions increased over time; positive emotions did not show such a pattern. Job satisfaction correlated positively with average positive emotions and negatively with average negative emotions. Neuroticism correlated significantly and in opposite directions with average positive and negative emotions, but did not correlate significantly with the variability of emotions within a work day. Additionally, neuroticism had a significant moderating effect on the changing pattern of negative (but not positive) emotions over time, such that the negative emotions of workers with high levels of neuroticism increased more sharply than the negative emotions of workers with low levels of neuroticism. Contrary to expectation, job satisfaction did not moderate the pattern of positive or negative emotions at work. Changing patterns of negative emotions may be predictive of occupational accidents and diurnal patterns of positive emotions may be predictive of optimal concentration and efficiency at work. These patterns may also have implications for when we administer surveys in the workplace, when a boss should share bad news with his/her employees.
\end{abstract}

Key words : Affect/Emotion; dynamics; Neuroticism; Job Satisfaction; variability; Day Reconstruction Method

\footnotetext{
* This work was supported by the National Research Foundation of Korea Grant funded by the Korean Government (NRF-2010-1-B00848)

† Corresponding Author : Jae Yoon Chang, Sogang University, jych@sogang.ac.kr
} 
Research on affect and emotion clearly indicates that affect levels fluctuate over time and that the patterns of these fluctuations are predictable to a great extent (Eid \& Diener, 1999; Moskowitz \& Zuroff, 2004). In the same vein, job affect is also inherently dynamic (Judge, Hulin, \& Dalal, in press), and the changing patterns of affective reactions may influence both overall feelings about one's job and discrete behaviors at work (Weiss \& Cropanzano, 1996). However it is unclear how much emotions fluctuate within a workday and what are the antecedents and outcomes of those fluctuations. Further, Weiss and Cropanzano (1996) claim "any analysis of affect as either a dependent or independent variable would require a full consideration of the fluctuation of affect levels over time" (p.42).

Affective Events Theory (AET; Weiss \& Cropanzano, 1996) proposes that time should be an important parameter when examining affect and job attitudes. Fundamental to AET is the idea that affect levels fluctuate over time, and that the causes of these patterns of affect can be examined in terms of endogenous components, such as known cycles in mood or affective dispositions, and exogenous components, such as affectively relevant events which constitute shocks to existing patterns (Weiss \& Cropanzano, 1996). Dispositions can also influence the way events produce affective reactions (e.g., Moskowitz \& Zuroff, 2004).

To investigate the dynamic patterns of affective reactions, researchers have pursued Experience Sampling Methodology (ESM) which permits momentary reports of emotions in one's natural environment. However, despite this new technique, the rhythmicity of affect within the workday has been understudied (Stone, Schwartz, Schwarz, Schkade, Krueger, \& Kahneman, 2006). This is in part because ESM studies are burdensome for participants and costly for investigators. As a result, most ESM studies are based on relatively small samples, and they are often limited to approximately four assessments per day (e.g., Ilies \& Judge, 2002; Weiss, Nicholas, \& Daus, 1999), which does not permit a full examination of the pattern of emotions experienced while one is working. In the present study, we use a relatively new and less invasive technique called the Day Reconstruction Method (DRM; Kahneman, Krueger, Schkade, Schwartz, \& Stone, 2004) which allows for the detection of finer-grained patterns of affect and has been shown to be a viable alternative to ESM (Stone et al., 2006).

Previous affect studies have acknowledged the likely difference between work and non-workdays (e.g., Ilies \& Judge, 2002; Stone et al., 2006); however, examinations of affect fluctuations have not been limited to time at work, nor examined relative to time spent at work rather than time of day. Studies of mood cycles within days, requiring multiple measurements throughout the day, occur infrequently, and formal analysis of moods cycles with data collected in work 
settings are relatively rare (Weiss \& Cropanzano, 1996).

Stone et al. (2006) revealed bimodal patterns for both positive and negative emotions over the course of a full day (including nonwork time). Our study takes Stone et al.'s (2006) investigation one step further by narrowing the scope of time examined to time at work in order to better reveal how much emotions fluctuate within that time span. We examine how positive and negative emotions fluctuate throughout the day, focusing exclusively on emotions while one is working relative to the amount of time worked. We also extend Stone's work by examining neuroticism and job satisfaction as moderators of the patterns of emotions at work.

\section{Changing Patterns of Emotions}

There have been many empirical studies examining the diurnal patterns of positive and negative emotions (for a review, see Watson, 2000). While some researchers have shown that energy levels and positive affect are highest in the morning (Wood, Magnello, \& Sharpe, 1992; Wood \& Magnello, 1992), Watson (2000) proposed that positive emotions tend to be lowest at the beginning and end of the day and highest in the middle of the day, when people are furthest temporally from sleep. $\mathrm{He}$ also suggested that negative emotions do not display diurnal patterns. However, participants in the studies he examined were mostly college students, and because of the sociocultural influence (e.g., a five day workweek) on daily emotional patterns, it is probable that their daily emotional patterns will differ from the patterns displayed by working individuals, as going to work likely plays a role in individual's emotions.

In a study of 94 workers, Stone, Smyth, Pickering, and Schwartz (1996) revealed diurnal cycles of most emotions were strongly associated with activities and location, yet some emotions (rushed, sad, and tired) revealed diurnal cycles independent of these factors. Emotions often changed at 5pm (when it was assumed that most participants were likely leaving work) and at noon (assumed lunch break), which demonstrated the psychosocial significance of certain temporally entrained events and locations contributed to the diurnal cycle in emotions.

Stone et al. (2006) found that positive emotions (happy, warm, and enjoy) and one negative emotion (tired) were significantly higher in the evening hours than the morning hours for a sample of 909 working women. When interpreting these same data, Kahneman et al. (2004) attributed the high levels of positive affect to social activities with friends, relatives, spouses, and children. When explaining the peaks in the patterns of emotions, authors often make inferences about work and nonwork based on assumptions regarding regularly scheduled activities for most people on a workday (i.e., leaving work at $5 \mathrm{pm}$ ), rather than examining 
the data with regard to individually reported information regarding location (e.g., work or home). Stone et al. (2006) acknowledged that "these events do not occur at exactly the same time for all working people" (p.140). Therefore, we argue it would be valuable to consider each individual's working hours rather than making assumptions about when people are most likely to arrive at or leave work.

We speculate that positive affect is likely to diminish and negative affect is likely to increase over time (cf. Watson, 2000). Within the workplace, there are many different factors that can cause a job to be stressful for an individual (Spector, 2002). These stressors include interpersonal problems, heavy workloads, and boring or repetitive work. The experience of stress in a work setting is a "widespread phenomenon" (Sonnentag \& Frese, 2003, p. 453). High levels of work demands and daily stress are associated with negative affect (Bolger, DeLongis, Kessler, \& Schilling, 1989; Rothbard, 2001). Emotional labor may lead to emotional exhaustion and burnout for employees over time (Grandey, Fisk, \& Steiner, 2005). Emotional labor is a form of emotional regulation wherein workers are expected to display certain emotions to others (e.g., customer) as part of their job. Suppression of emotions can decrease an individual's level of positive emotions (Gross, 2002). This is not limited to certain occupational groups, as many jobs encompass such interpersonal job demands (Diefendorff \&
Richard, 2003). Therefore, as most workers in today's workplace perceive emotional display rules, their experienced emotions will likely become more negative over time even though they might express or display positive emotions to others. Because there is so little known about the pattern of emotions experienced while one is working, we tentatively propose the following exploratory hypothesis.

Hypothesis 1a. Positive emotions will decrease throughout one's workday.

Hypothesis 1b. Negative emotions will increase throughout one's workday.

\section{Affect Variability and Moderating Effects}

Intra-individual variability in affect is different from the average level of affect and therefore reflects different aspects of one's emotional life. Individual differences in affect variability are important in understanding affective experiences as affect variability typically measured by intraindividual standard deviation is so stable that it can be considered a psychological trait (Eid \& Diener, 1999). One of the purposes of this study is to extend current knowledge of intra-individual variability in affect within a workday. A group of variables likely to influence mean level and variability in affect is dispositional characteristics (cf. Weiss \& Cropanzano, 1996). Some people, simply because 
of their personality, are likely to experience more variation in their emotions (Larsen \& Kasimatis, 1990). In this study, we examine neuroticism given their theoretical relevance to affect (Staw, Bell, \& Clausen, 1986).

\section{Neuroticism}

Neuroticism describes a pervasive disposition to experience aversive states such as anxiety, anger, and sadness (Watson, 2000). Thus, individuals with a high level of neuroticism are more likely to experience distress and negative emotions even in the absence of objective stressors. They also tend to cope less effectively with stress and have a tendency to view events as threatening and troubling. Additionally, individuals with a high level of neuroticism react more strongly to negative stimuli than do those who have lower levels of neuroticism (Gross, Sutton, \& Ketelaar, 1998). As such, if a situation is perceived as negative or one that an individual does not enjoy, a person with a high level of neuroticism would likely react quite negatively. In an experimental study, Larsen and Ketelaar (1991) found that individuals high in neuroticism reacted primarily to the negative events, and they were relatively nonreactive to the neutral and positive stimuli. In a longitudinal study, Bolger and Schilling (1991) showed that in various settings, including the workplace, individuals high in neuroticism were more likely to argue and quarrel with others, and this tendency to fight was actually one cause of negative mood.

Although individuals with a high level of neuroticism are more likely to experience negative emotions, this does not preclude them from experiencing positive emotions. However, this experience of positive emotions occurs only when the situation in which they are involved is enjoyable or pleasant $(\mathrm{Ng}, 2009)$, so it is still likely that individuals high on neuroticism will experience less positive emotions at work, given that the day on a whole will likely not be composed of only pleasant situations. Furthermore, Brief, Butcher, and Roberson (1995) posited that individuals with a high level of negative affectivity (NA) might respond with diminished pleasure when experiencing positive job events. They attributed such a possibility to high NA individuals having a higher threshold for positive stimuli and a low-magnitude positive mood reaction to positive events. Tan, Foo, Chong, and $\mathrm{Ng}$ (2003) also demonstrated that neuroticism was negatively related to displayed positive emotions among retail chain store employees. Therefore, we expect neuroticism to be negatively related to the average level of positive emotions experienced throughout the workday and positively related to the average level of negative emotions experienced throughout the workday.

Hypothesis 2a. Neuroticism will be negatively related to the average level of positive emotions 
experienced within a workday.

Hypothesis 2b. Neuroticism will be positively related to the average levels of negative emotions experienced within a workday.

In addition to the mean level of affect, the most important and powerful personality variable for intraindividual affect variability was neuroticism, because it was related to the variability in all negative affect categories and to the positive affect of love (Eid \& Diener, 1999).

A number of studies have demonstrated that there is a relationship between neuroticism and variability in mood (e.g., Eid \& Diener, 1999; Eysenck \& Eysenck, 1985; Ilies \& Judge, 2002; Murray, Allen, \& Trinder, 2002). For example, using ESM, neuroticism was shown to correlate .38 with within-individual variability in negative affect (Ilies \& Judge, 2002) and was the only one of the Big Five personality traits to emerge as a predictor of mood variability (Murray et al., 2002). Individuals high in neuroticism are more likely to experience higher levels of negative affect. As a result, they experience more variability in negative affect because they have a wider range of affect than those lower in neuroticism (Eid \& Diener, 1999; Eysenck \& Eysenck, 1985; Williams, 1990).

Hypothesis 2c. Neuroticism will be positively related to the variability of negative emotions experienced within a workday.
Some research on individuals high in neuroticism has demonstrated a lag or carryover effect in which prior mood tends to carry over to subsequent time periods (Suls, Green, \& Hillis, 1998). Suls et al. (1998) showed that people with a high level of neuroticism were likely to continue to be in a poor affective state if they experienced negative emotion during the immediately preceding time period. Combining this idea of a lag or carryover effect with the expectation that high neuroticism individuals will have greater variability in their negative emotions than those lower on neuroticism, we speculate high neuroticism workers will experience greater rates of increase in their negative emotions during the workday than lower neuroticism workers. The negative emotions of individuals high on neuroticism build on the negative emotions of the previous time period and therefore lead to a steeper increase in negative emotions.

While there is more support for neuroticism as a predictor of variability of negative emotions, some research suggests that it can predict variability in positive emotions as well, although the relationship with positive emotion variability is weaker than the relationship with negative emotion variability (Murray et al., 2002).

Hypothesis 2d. The positive emotions of individuals with a high level of neuroticism will decrease more sharply throughout one's workday than the positive emotions of individuals with a low level 
of neuroticism.

Hypothesis 2e. The negative emotions of individuals with a high level of neuroticism will increase more sharply throughout one's workday than the negative emotions of individuals with a low level of neuroticism.

\section{Job Satisfaction}

Affect or mood on the job is an important component of job attitudes and predictor of some job behaviors (Brief \& Weiss, 2002; Weiss \& Cropanzano, 1996). As such, it can be expected that if an individual recalls positive emotions during work episodes, s/he will have higher levels of job satisfaction than if $s / h e$ recalls less positive emotions. Likewise, individuals reporting more negative emotions will have lower job satisfaction than those recalling less negative emotions. Weiss et al. (1999) showed that average pleasant mood measured during 16 days significantly predicted overall job satisfaction. Fisher (2000) also showed that real time affect measured using ESM over a two week period is significantly related to overall job satisfaction, and positive and negative emotions both make unique contributions to predicting overall satisfaction. Meta-analytic results have shown a positive relationship between positive affect and job satisfaction and a negative relationship between negative affect and job satisfaction (Thoresen, Kalan, Barsky, Warren, \& de Chermont, 2003), however these relationships are not based on the emotions that are measured over a full work day. We expect that the average levels of positive and negative emotions experienced during a workday will be significantly related to an individual's level of job satisfaction.

Hypothesis 3a. Job satisfaction will be positively related to the average level of positive emotions experienced within a workday.

Hypothesis 3b. Job satisfaction will be negatively related to the average level of negative emotions experienced within a workday.

We propose that an individual's job satisfaction level will attenuate the changes in positive and negative emotions experienced throughout the workday. Individuals with a high level of job satisfaction perceive the workplace and time spent in it as a desirable situation or environment. In contrast, individuals with a low level of job satisfaction perceive work as a less desirable environment. We propose that a high level of job satisfaction can serve as a buffer for naturally occurring diurnal rhythms of emotions, such that individuals with a high level of job satisfaction will experience less of a decline in positive emotions and less of an increase in negative emotions throughout the workday.

Hypothesis 3c. The positive emotions of individuals with a high level of job satisfaction will decrease less sharply throughout one's workday than the positive 
emotions of individuals with a low level of job satisfaction.

Hypothesis 3d. The negative emotions of individuals with a high level of job satisfaction will increase less sharply throughout one's workday than the negative emotions of individuals with a low level of job satisfaction.

\section{Method}

\section{Participants}

Our initial sample consisted of 300 working adults in South Korea who were recruited from a professional survey firm subject pool, which is representative of the population of employed Seoul citizens. Voluntary participation was requested via e-mail, and participants received approximately $\$ 80$ for their participation. Among the 300 respondents, we excluded participants who 1) started work before 11am, 2) worked at least 6 hours on the focal day, 3) worked on average at least four days a week, and 4) reported the day they described as fairly typical [we excluded respondents who responded 1 (much worse) or 5 (much better) to the following item: "Now we'd like to know how typical yesterday was for that day of the week. Compared to what that day of the week is usually like, yesterday was _ "'].

The final sample consisted of 201 respondents (67\% of the initial sample). Sixty-five percent were male. The average age of the respondent was 34.5 years $(S D=3.66)$, ranging from 28 to 42 . With regard to education almost $90 \%$ of the participants had at least 2 years of college education. The modal response for household income was $\$ 40-50 \mathrm{k}$.

\section{Procedure}

As previously noted, we used the DRM (Kahneman et al., 2004) to measure changes in workers' emotions in a workday. The DRM was developed to allow for the assessment of activities and affect of the previous day with minimal recall bias. Participants are asked to systematically reconstruct their activities and experiences for the preceding day on a questionnaire with procedures designed to reduce retrospection bias. It is a less expensive, invasive, and time consuming alternative to ESM (Csikszentmihalyi \& Larson, 1987) and researchers have shown this method successfully reproduces a complex pattern of various affects and emotions (Kahneman et al., 2004).

Though DRM is technically retrospective, it is different from global retrospective reports in that it requires participants to recall specific and recent episodic memories, which should promote accuracy (Robinson \& Clore, 2002). Furthermore, as the DRM covers a full day and not just a few snapshots of the day, it can sample a variety of different situations and events within a single day. Thus, DRM fits our research purpose 
well, as it allows for examination of the flow of affective responses throughout a workday.

Participants completed questionnaire packets in groups in a large conference room under the direction of the principal investigator. First, they completed demographics, individual difference variables, and job satisfaction. Then, they wrote a short diary consisting of consecutive episodes corresponding to events of their previous workday.

Participants were instructed to think carefully about everything they did from waking up until going to sleep. They then divided the day into discrete episodes, naming each episode and reporting the approximate times at which each began and ended. These episodes represent the ebb and flow of emotional experience over time (Frijda, 1993). Finally, participants answered structured questions about each episode. The questions included location (home, work, in a car, or elsewhere), activity, with whom they were interacting and their emotion during the episode. Participants reported an average of 8.12 $(S D=2.26)$ episodes. The questionnaire took approximately 1.5 hours to complete.

\section{Measures}

Positive and Negative Emotions were measured with five adjectives each which were used in Kahneman et al. (2004) study. Positive emotions were assessed with competent/confident, interested/focused, happy, affectionate/friendly, and calm/relaxed, while negative emotions were assessed with irritated/angry, depressed/blue, tense/stressed, tired, and impatient for it to end. Response scales for the adjectives ranged from 0 (not at all) to 6 (very much), with the intermediate points unlabeled. Consistent with the majority of studies on affect fluctuation, we measured affect variability with the intra-individual standard deviation (e.g., Eid \& Diener, 1999).

Job satisfaction was measured using the following single item: Overall, how satisfied are you with your present job? The response scale for this item included the following anchors: $4=$ very satisfied, $3=$ satisfied, $2=$ not very satisfied, and $1=$ not at all satisfied. Prior research has shown single-item measures are highly correlated with multiple-item measures, which indicates that the use of a single-item measure in order to condense a survey and increase response rate is justified (Wanous, Reichers, \& Hudy, 1997).

Neuroticism was measured using the following six items from the International Personality Item Pool (Goldberg, 1992) neuroticism scale: I worry about things, I get upset easily, I have frequent mood swings, I get irritated easily, I often feel blue, and I get stressed out easily. Response scales ranged from 1 (not at all) to 7 (very much).

\section{Data Arrangements and Analyses}

We followed Stone et al.'s (2006) procedure for identifying the timing of DRM episodes, 
which are defined by the individually reported beginning and end times. For the multilevel analysis, we used each episode's midpoint (the average of starting and ending times) to represent when the episode occurred. This midpoint was categorized into 17 one-hour blocks (e.g., 9:00-9:59) between 7:00am and 11:00pm. If the duration of the episode covered more than 1 hour (e.g., 2 hours), the emotions were assigned to all of the 1-hour time blocks that occurred within that episode. For example, if an episode occurred from 10:00am to 12:00pm the emotion ratings associated with that episode were assigned to both the 10:00am and 11:00am time blocks. If there was more than one episode that occurred in the same one-hour block, the episode with the longer duration in that time block was entered. This categorization into one-hour time blocks allows the data to represent the finer dynamics of emotions in a work day.

Based on the question about location for each episode, we determined when the respondents started and ended work. On average, respondents worked 9.59 hours ( $S D=1.42$ ). Working times ranged from 7:00am to 9:00pm time block. Starting time ranged from 7:00am to 10:00am, with about $65 \%$ starting during the 9:00am block. This starting hour means that the first work episode was reported during that time block. Ending work time was more diverse than starting time, ranging from the $1: 00 \mathrm{pm}$ to the 9:00pm block. About 55\% ended their work during the 5:00pm block.

To test Hypotheses 2a, 2b, 3a and 3b, we used hierarchical multiple regression with demographic variables and hours worked as controls. We used Hierarchical Linear Modeling (HLM) to test Hypotheses 1a, 1b, 2d, 2e, 3c, and 3d (Raudenbush,\& Bryk, 2002). HLM is generally preferable in situations such as this, because it allows for unequal numbers of repeated measures, missing data, autocorrelation among repeated measures, and various error structures. We tested the temporal dynamics of emotions by including one-hour time block (TB) variable as a continuous within-subject predictor (level 1) and neuroticism and job satisfaction variables as between-subject predictors (level 2) using HLM 6 (Raudenbush, Bryk, \& Congdon, 2004).

\section{Results}

Descriptive statistics and correlations are presented in Table 1. Surprisingly, the number of hours worked in the focal day was not significantly related to job satisfaction, positive emotions, or negative emotions. The relationship between average positive and negative emotions was not significant $(r=.02, p>.05)$, indicating that these two composite variables are independent. This is consistent with the view of two-dimensional structure of the valence of affect (Diener \& Emmons, 1984; Watson \& Tellegen, 


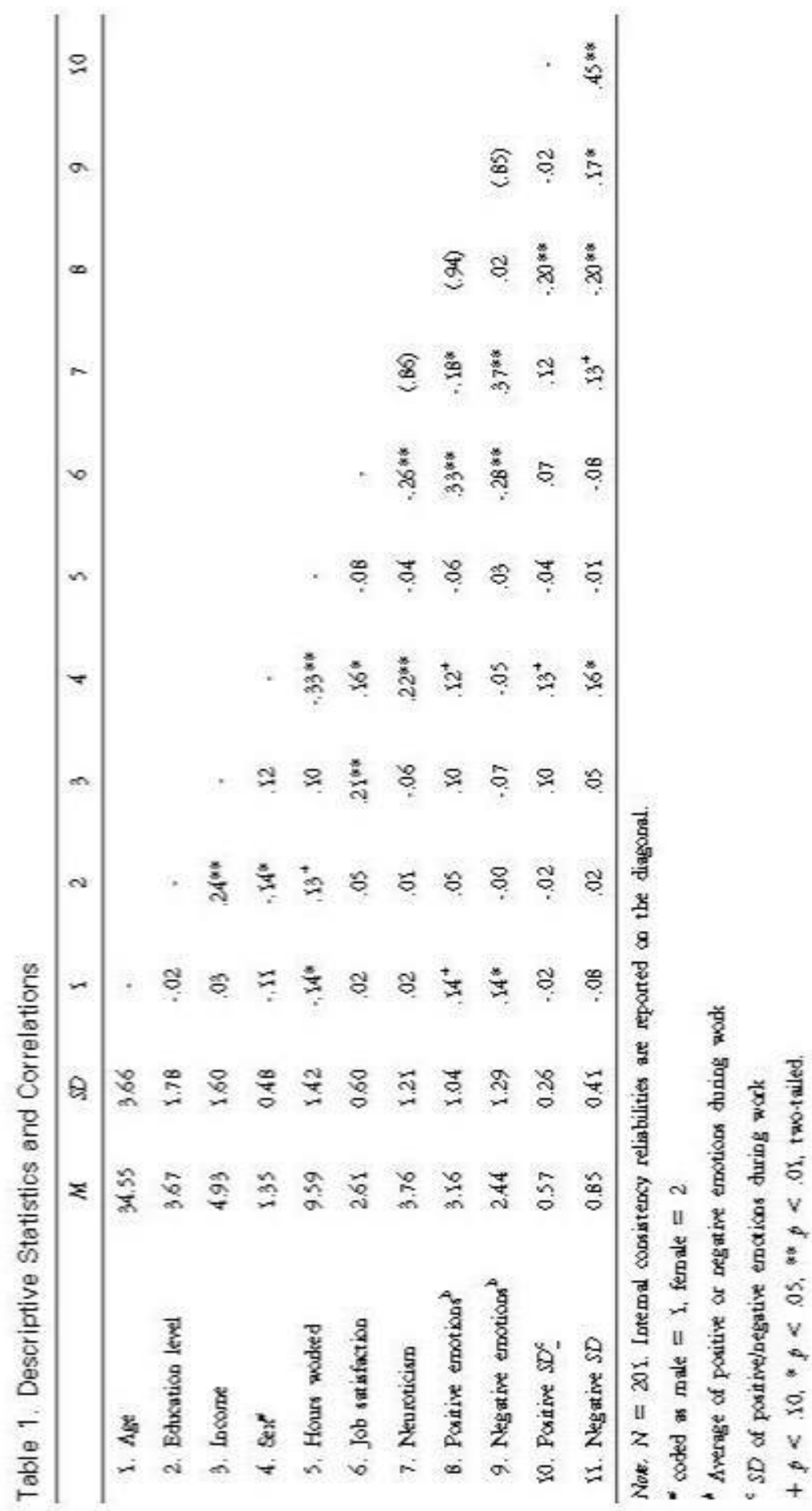


1985).

As expected, neuroticism was significantly correlated with both positive and negative emotions, in opposite directions, demonstrating a negative correlation with positive emotions $(r=$ -.18, $p<.05)$ and a positive correlation with negative emotions $(r=.37, p<.01)$. The results of the regression analyses also showed that neuroticism was significantly related to positive $(\beta=-.22)$ and negative $(\beta=.39)$ emotions, after controlling for demographic variables and hours worked (Table 2). These results supported Hypotheses $2 \mathrm{a}$ and $2 \mathrm{~b}$. Concerning affect variability, neuroticism was not significantly correlated with variability $(S D)$ of both positive and negative emotions, though the correlation between neuroticism and variability of negative emotion approached significance. Furthermore, the results of the regression analysis also showed that neuroticism was not

Table 2. Regression Analysis Results for Average Positive and Negative Emotions

\begin{tabular}{|c|c|c|c|c|}
\hline Variable & \multicolumn{2}{|c|}{$\beta t$} & \multicolumn{2}{|c|}{$\beta t$} \\
\hline \multicolumn{5}{|c|}{ Average Positive Emotion } \\
\hline \multicolumn{5}{|l|}{ Step 1} \\
\hline Age & .142 & $2.067 *$ & .163 & $2.311 *$ \\
\hline Education level & .051 & .721 & .076 & 1.062 \\
\hline \multicolumn{5}{|l|}{ Income } \\
\hline Sex & .012 & .172 & .045 & .615 \\
\hline \multirow[t]{2}{*}{ Hours worked } & .093 & 1.250 & .191 & $2.451 *$ \\
\hline & .005 & .064 & .000 & -.010 \\
\hline \multicolumn{5}{|l|}{ Step 2} \\
\hline Job satisfaction & .308 & $4.456 * *$ & & \\
\hline Neuroticism & & & -.220 & $-3.112 * *$ \\
\hline \multicolumn{5}{|c|}{ Average Negative Emotion } \\
\hline \multicolumn{5}{|l|}{ Step 1} \\
\hline Age & .155 & $2.211 *$ & .123 & $1.822+$ \\
\hline Education level & .022 & .304 & -.015 & -.213 \\
\hline \multicolumn{5}{|l|}{ Income } \\
\hline Sex & -.025 & -.343 & -.034 & -.484 \\
\hline \multirow[t]{2}{*}{ Hours worked } & .028 & .373 & -.112 & -1.505 \\
\hline & .036 & .479 & .029 & .409 \\
\hline \multicolumn{5}{|l|}{ Step 2} \\
\hline Job satisfaction & -.285 & $-4.055 * *$ & & \\
\hline Neuroticism & & & .387 & $5.710 * *$ \\
\hline
\end{tabular}

Note. $+p<.10, * p<.05, * * p<.01$. 
significantly related to variability of negative emotions $(\beta=.10)$, after controlling for demographic variables and hours worked, failing to support Hypothesis 2c.

Job satisfaction was positively correlated with average positive emotions $(r=.33, p<.01)$ and negatively correlated with average negative emotions $(r=-.28, p<.01)$. After controlling for demographic variables and hours worked, job satisfaction was significantly related to average positive $(\beta=.31)$ and average negative $(\beta=$ -.29) emotions (see Table 2). Thus both Hypotheses $3 \mathrm{a}$ and $3 \mathrm{~b}$ were supported. However, job satisfaction was not significantly correlated with affect variability at all.

The higher the average positive emotions, the lower the variability of both positive $(r=-.20$, $p<.01)$ and negative $(r=-.20, p<.01)$ emotions. The higher the average negative emotions, the higher the variability of negative emotions $(r=.17, p<.05)$.

Similar to previous research (e.g., Stone et al., 2006), a substantial proportion of the total variance in emotion scores was caused by episode-to-episode variation which shows the within-person, dynamic nature of affect on the job (Miner, Glomb, \& Hulin, 2005). Specifically, by using the null HLM models that were estimated for emotion variables measured repeatedly, we found that more than $36 \%$ of the total variance in the positive emotion was due to variation across times; similarly negative emotion scores varied substantially within individuals with more than $53 \%$ of the total variance caused by within-subject variation. Within-subject variation of negative emotions was larger than within-subject variation of positive emotions, showing higher mean $S D$ for negative emotions (.85) than that of positive emotions (.57).

To address whether there was an overall increase or decrease of emotions across the day (Hypotheses 1a and 1b), we examined the linear component of time for both positive and negative emotions. For these analyses, time block (TB) was treated as a continuous variable, using the following model (Model I):

Level 1 Model: Positive (Negative) Emotion

$$
=\pi_{0}+\pi_{1}(T B)+e
$$

Level 2 Model: $\pi_{0}=\beta_{00}+r_{0}$

$$
\pi_{1=} \beta_{10}+r_{1}
$$

Table 3 presents the HLM results of the analysis conducted to test Hypotheses $1 \mathrm{a}$ and 1b. The results showed that there was not a significant decrease in positive emotions during the workday $\left(\beta_{10}=-.01, S E=.01, t=-1.19\right)$. Therefore Hypothesis 1a was not supported. However, there was a significant increase in negative emotions $\left(\beta_{10}=.04, S E=.01, t=\right.$ 3.86), supporting Hypothesis 1b. This suggests that as time goes by during the workday, the negative emotions that workers experience gradually increase.

To investigate whether neuroticism moderated 
Table 3. Multilevel Analysis Results for the Positive and Negative Emotions

\begin{tabular}{|c|c|c|c|c|c|c|}
\hline \multirow{2}{*}{ Variable } & \multicolumn{3}{|c|}{ Positive Emotion } & \multicolumn{3}{|c|}{ Negative Emotion } \\
\hline & Coefficient & SE & $t$ & Coefficient & SE & $t$ \\
\hline \multicolumn{7}{|l|}{ Model I } \\
\hline Time $\operatorname{Block}(\mathrm{TB})\left(\beta_{10}\right)$ & -.009 & .007 & -1.194 & .035 & .009 & $3.862 * *$ \\
\hline \multicolumn{7}{|l|}{ Model II : Neuroticism } \\
\hline $\operatorname{Neuroticism}\left(\beta_{11}\right)$ & -.003 & .006 & -.413 & .015 & .007 & $2.043^{*}$ \\
\hline \multicolumn{7}{|c|}{ Model III: Job Satisfaction } \\
\hline $\operatorname{Job} \operatorname{Satisfaction}\left(\beta_{11}\right)$ & -.008 & .012 & -.637 & -.006 & .015 & -.421 \\
\hline \multicolumn{7}{|l|}{ Model IV: Combined } \\
\hline $\operatorname{Neuroticism}\left(\beta_{11}\right)$ & -.004 & .006 & -.609 & .016 & .008 & $1.991 *$ \\
\hline Job Satisfaction $\left(\beta_{12}\right)$ & -.010 & .013 & -.780 & .003 & .016 & .187 \\
\hline
\end{tabular}

Note. $* p<.05, * * p<.01$.

the within-participant relationship between emotions and time block (Hypotheses 2d and 2e), we estimated a second hierarchical linear model (Model II) which included neuroticism as a level 2 predictor. Model II included the following Level 2 Model:

Level 2 Model: $\pi_{0=} \beta_{00}+\beta_{01}($ Neuroticism $)+r_{0}$ $\pi_{1=} \beta_{10}+\beta_{11}($ Neuroticism $)+r_{1}$

Predictors in level 2 were all about their respective grand means.

As shown in Table 3, there was not a significant slope change by neuroticism for positive emotions $\left(\beta_{10}=-.00, S E=.01, t=\right.$ -.41). Thus Hypothesis $2 \mathrm{~d}$ was not supported. However, there was a significant slope change for negative emotions $\left(\beta_{10}=.02, S E=.01, t\right.$ $=2.04$ ), supporting Hypothesis 2e. This means that that the negative emotions of workers with a high level of neuroticism increased more rapidly than did those of workers with a low level of neuroticism.

Finally, to test Hypotheses $3 c$ and $3 d$, we estimated a third model which was the same as Model II, except job satisfaction was substituted for neuroticism. As shown in Table 3, there were no significant slope changes for positive or negative emotions; therefore, Hypothesis $3 c$ and $3 \mathrm{~d}$ were not supported.

Additionally, we estimated another model (Model IV) including both neuroticism and job satisfaction as moderators in the level 2 equation at the same time to examine their joint effects. 
Consistent with the above findings, these results showed that only neuroticism had significant moderating effect on negative emotions $\left(\beta_{10}=\right.$ $.02, S E=.01, t=1.99$ ).

Figure 1 displays the results of analysis of Model IV, showing the joint effects of two moderators on the relation between time and negative emotions. Workers with a high level of neuroticism showed increasingly higher levels of negative emotion as the workday passed by than workers with a low level of neuroticism. Even highly satisfied workers showed this same pattern of increasing negative emotions.

According to the circumplex model of affect, emotions share two basic dimensions: hedonic valence (pleasant-unpleasant) and intensity of arousal (high vs. low activation; Larsen \& Diener, 1992; Russell, 1980). Previous research has firmly established that activated unpleasant affect is strongly related to neuroticism (Watson, 2000). As a supplementary analysis, we investigated whether the moderating effect of neuroticism generalized across different categories of negative emotions. Based on the circumplex

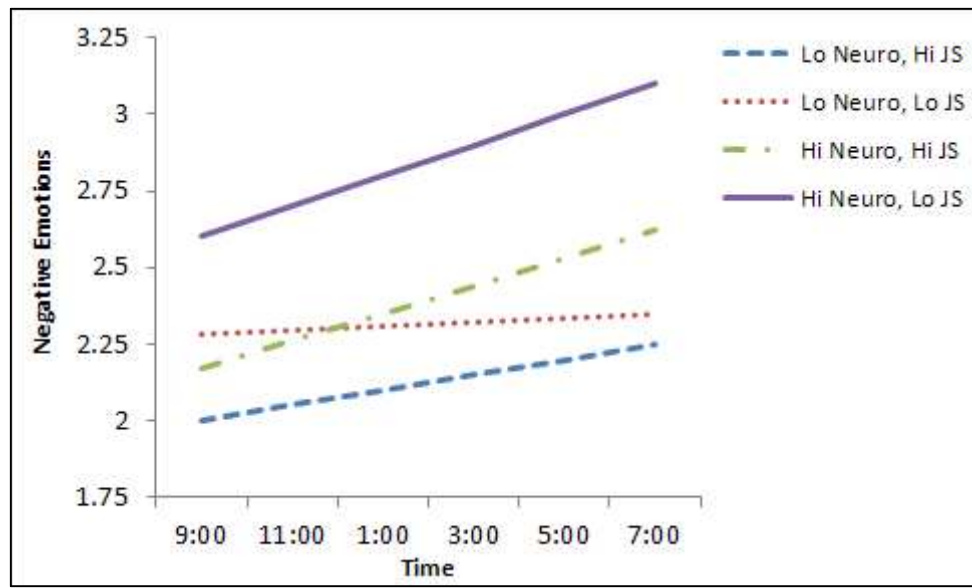

Figure 1. Change in Negative Emotions at Work for Varying Levels of Neuroticism and Job Satisfaction

Table 4. Multilevel Analysis Results for the Two Types of Negative Emotions

\begin{tabular}{lcccccc}
\multicolumn{1}{c}{ Variable } & \multicolumn{2}{c}{ Negative-inactivated Emotion } & \multicolumn{3}{c}{ Negative-activated Emotion } \\
& Coefficient & SE & $t$ & Coefficient & SE & $t$ \\
\hline Model V & & & & & & \\
Neuroticism $\left(\beta_{11}\right)$ & .011 & .009 & 1.146 & .019 & .009 & $2.236^{*}$ \\
Job Satisfaction $\left(\beta_{12}\right)$ & .005 & .019 & .269 & .003 & .017 & .193 \\
\hline
\end{tabular}

Note. $* p<.05$ 
model, we divided negative emotions into two types, negative-activated (Irritated/Angry, Tense/ Stressed, Impatient for it to end) and negative-inactivated emotions (Depressed/Blue, Tired) in order to examine if intensity of emotion activation plays a role in the temporal patterns of negative emotions at work.

Results of these HLM analyses (Model V) show a significant slope change in negativeactivated emotions, but not in negativeinactivated emotions (see Table 4), suggesting the increase of negative emotions in a work day is primarily due to an increasing negative-activated emotions.

\section{Discussion}

In an effort to contribute to our understanding of the variability of affect in the workplace, this study examined the temporal dynamics of positive and negative emotions in a workday and the moderating effects of neuroticism and job satisfaction using the DRM approach.

Contrary to our predictions, positive emotions did not demonstrate a significant decrease throughout one's workday. Though several earlier studies (Stone et al., 2006; Wood et al., 1992) reported that positive, but not negative, emotions show diurnal cycles in a day, we did not demonstrate a salient downward changing pattern of positive emotions. This may be due to limiting the time frame of investigation to working hours. Weiss et al. (1999) also found pleasant moods increase slightly and then plateau throughout the workday. In general, positive emotions are relatively stable throughout one's workday as they have lower levels of variability than negative emotions. As work is often a source of perceived competence, flow, and positive social exchange (Csikszentmihalyi \& LeFevre, 1989; Sheldon, Ryan, \& Reis, 1996), these positive outcomes may counter the decreasing pattern of positive emotions at work On the other hand, if positive emotions are more likely to be influenced by situational factors than dispositional factors, some job attributes, like job control or autonomy, may have moderating effects on the temporal dynamics of positive emotions. For example, Fullagar and Kelloway (2009) showed that $74 \%$ of the variance in positive experiences was attributable to situational characteristics rather than dispositional factors.

In the current study, negative emotions gradually increased throughout one's workday and showed more variability than positive emotions. At work, stressful episodes (e.g., dealing with angry customers, long tedious meetings with boss) may negatively affect employee's moods and emotions, and the effects of stress may also build over time, As the mounting levels of stress and strain at work can worsen affect, causing more negative emotions over time (Fuller, Stanton, Fisher, Spitzmüller, \& 
Russell, 2003).

Various researchers have argued that emotion regulation requires the expenditure of a limited pool of cognitive and energy resources (Brotheridge \& Lee, 2002; Grandey, 2000; Muraven \& Baummeister, 2000). For example, according to the limited resources (self-control strength) model (Muraven \& Baummeister, 2000), controlling one's own feeling and behavior (self-control) requires the expenditure of some inner, limited resource that is depleted afterward. The resource needed for self-control is partially consumed in the process of self-control, and a depletion of strength (resource) may result in breakdown of self-control. Then, resource (strength) resembles a muscle that becomes fatigued by exertion and becomes less able to function, and so the exertion of self-control should consume resources more quickly than they can be replaced, thereby resulting in a net decrease in available resources. This model can give a hint about the increasing pattern of negative emotions over time within a workday, though we did not have corresponding measures of self-control or depletion. That is, as time goes by, and stress and strain accumulate, workers may lose resources they need to control one's negative emotions. This is why we need psychological detachment from work during off-job time to recover from stress and negative emotions at work (Sonnentag \& Kruel, 2006).

In the present study, neuroticism had a significant relationship with average emotions in a workday. Previous studies indicate that individuals with a high level of neuroticism are prone to experience a diverse array of negative emotions and display less positive emotions. Supporting this idea, the current study showed that neuroticism was positively related to negative emotions and negatively related to positive emotions within a workday. The negative relationship between neuroticism and positive emotions could be attributed to the high threshold for positive stimuli and a low-magnitude positive affect reaction to positive stimuli (Brief et al. 1999; Brief \& Weiss, 2002). Brief et al. (1995) posited that individuals with a high level of NA might respond with diminished pleasure when experiencing positive job events. They observed a positive mood induction had less of an effect on job satisfaction among individuals high in NA.

Contrary to our expectation and Ilies and Judge's (2002) results, neuroticism was not significantly related to variability of negative emotions within a work day. Perhaps the inconsistency could be explained by the fact that Ilies and Judge (2002) examined emotions over an extended period of time.

However, it appears that individuals with high levels of neuroticism experience greater increases in negative emotions at work than workers who report lower levels of neuroticism. It could be that those high in neuroticism have a greater propensity to perceive the day as more negative as it progresses. This can be explained more 
persuasively by the idea of 'escalation of negative emotions' based on the lag or carryover mechanism, which may be contributing to the higher level of negative emotions reported by individuals with a high level of neuroticism (Suls et al., 1998). That is, more neurotic individuals were likely to continue to be in a poor mood if they were in a poor mood during the immediately preceding time period. This is especially true when the interval is relatively short, as is the case in the current study (Stone, Neale, \& Shiffman, 1993). Individuals with a high level of neuroticism may exhibit the most marked affective inertia for negative mood, which might be the result of the use of inappropriate or maladaptive coping efforts to handle problems or repair mood (Suls et al., 1998). Recently Kuppens, Allen, and Sheeber (2010) found that emotional inertia is significantly related to psychological maladjustment.

Furthermore, exploratory analyses revealed that negative-activated emotions were particularly prone to this pattern of increasing negative emotions. According to self-control strength model (Muraven \& Baummeister, 2000), after one difficult attempt at self-control, subsequent attempts at self-control should be less likely to succeed. As neuroticism is associated with emotional unstability or the lack of emotional self-control, we can say that high neurotics have fewer resources for self control. Self-control strength is used and consumed any time the self actively initiates, alters, or stifles a response.
Because the success of self-control may depend on the amount of resources available to the person, a decrease in strength may result in less self-control. This model emphasizes how self-control performance declines over time following consecutive attempts at self-control. So, neurotic workers might have more difficulty in controlling their emotions over time because they have less resource left to control their emotions.

Consistent with expectation, job satisfaction was positively related to the average of episodic positive emotions and negatively related to the average of episodic negative emotions experienced in one workday. These results are consistent with Weiss et al. (1999) and Ilies and Judge's (2002) research findings. Considering our measure of job satisfaction was a global evaluation of the job, this result indicates that job satisfaction is related to the summative affective states during the workday. Furthermore, our study replicated the significant relationship between affective reactions on the job and job satisfaction within a work day. Finally, contrary to our expectation that that job satisfaction would color the way work events are interpreted and have buffering effects of positive and negative events or cycles, the results showed that job satisfaction did not have any such effects on emotional response at work.

\section{Practical Implications}

This study reveals why organizations should 
capitalize on the morning time given negative emotions appeared to increase throughout the workday. This has implications for when we administer surveys in the workplace, when a boss should share bad news with his/her employees, and when a customer might want to confront a customer service representative. Specifically, we should be cautious when we gather attitudinal data (e.g., job satisfaction) which could be strongly influenced by one's emotional state. It is possible that we could get somewhat different results between an attitude measure collected in the morning and one collected in the late afternoon. Job satisfaction is often assessed at some arbitrary point in time without giving any consideration of affective experience over time (Weiss \& Cropanzano, 1996). In fact, the cognitive judgment approach to job satisfaction focuses on the effects of environmental features because such features are considered relatively stable, and treats daily or episodic affective fluctuations as error.

In our study, neuroticism had a dynamic effect on negative emotional responses in a work setting. This may validate the use of personality inventories to select individuals for jobs that strongly require employees to control negative emotions for long work hours. Another strategy to mitigate the detrimental effects of a high level of neuroticism might be to reduce or remove stressors in the work environment or to provide stress-management techniques for employees, especially when the organizational context is stressful (Kaplan, Bradley, Luchman, \& Haynes, 2009).

Diurnal patterns of negative emotions may be predictive of occupational accidents (Fortson, 2004; Reid, 1928) and diurnal patterns of positive emotions may be predictive of optimal concentration and efficiency at work (Stone et al., 2006). These patterns may also have implications for start and stop times for shift work, as well as other scheduling decisions.

Finally, negative emotions were higher in the late afternoon, before employees leave work and shift into a nonwork setting. So, the temporal dynamics of emotion in a day may also shed some light on the spillover of negative emotions from the work to family domain. For example, we can expect that workers high on neuroticism may arrive home with a high level of negative emotions, especially the negative-activated emotions, which represent a low level of emotional control and regulation. In addition to the finding that negative mood is more likely to cross the work-family boundary than positive mood (e.g., Williams \& Alliger, 1994), this study further showed the possibility that the spillover of negative emotions to home may occur more easily for workers high on neuroticism than for low neuroticism workers.

\section{Limitations and Future Research Suggestions}

Weiss et al. (1999) highlighted "it is 
important to emphasize that identifying these cycles is not the same as explaining them" (p. 21). We have started to explain when diurnal changes may occur (i.e., with high levels of neuroticism), however there is still much to be learned about why these patterns of positive and negative emotions occur. Cycles in emotions can arise from many different sociocultural and biological factors (Watson, 2000) and more specific contextual factors like job attributes and leadership (Bono, Foldes, Vinson, \& Muros, 2007). Correspondingly, additional research is needed to illuminate the driving factors behind these changing patterns of emotions, and to examine the consistency of diurnal patterns of emotions across multiple workdays.

The time $\mathrm{X}$ neuroticism interaction for negative emotions might be due to high neurotic workers recalling more negative events as they mentally process the previous workday. Thus, the increase in negative affect may reflect the accumulation of negative events recalled and reported in the diaries. This raises the question of whether high neurotic workers actually experienced more negative affect, or they are just recalling more negative emotions as a function of their focus on negative events. This is a problem with using the recall method for studying emotions. However, despite the retrospective nature of the DRM, the instructions encouraged participants to take the time to relive each episode in detail. This evokes the contextual experience, as opposed to the semantic and decontextualized remembering of self that is typically associated with retrospective reports of emotions (Robinson \& Clore, 2002).

In order to examine changes in emotions within a workday as a function of time spent at work, we structured our data relative to the time participants reported starting work. This required us to make some judgment calls when creating one-hour time blocks that aligned across participants. Future research may want to conduct even more fine-grained analyses on time block. Additionally, we might need to examine the consistency of diurnal patterns of emotions across multiple workdays and gather additional situational variables that are likely to contribute to fluctuations in emotions.

\section{References}

Bolger, N., DeLongis, A., Kessler, R. C., \& Schilling, E. A. (1989). Effects of daily stress on negative mood. Journal of Personality and Social Psychology, 57, 808-818.

Bolger, N., \& Schilling, E. A. (1991). Personality and the problems of everyday life: The role of neuroticism in exposure and reactivity to daily stressors. Journal of Personality, 59, 355-386.

Bono, J. E., Foldes, H. J., Vinson, G., \& Muros, J. P. (2007). Workplace emotions: The role of supervision and leadership. Journal of Applied Psychology, 92, 1357-1367.

Brief, A. P., Butcher, A. H., \& Roberson, L. (1995). Cookies, disposition, and job attitudes: 
The effects of positive mood-inducing events and negative affectivity on job satisfaction in a field experiment. Organizational Behavior and Human Decision Processes, 62, 55-62.

Brief, A. P., \& Weiss, H. M. (2002). Organizational behavior: Affect in the workplace. Annual Review of Psychology, 53, 279-307.

Brotheridge, C. M., \& Lee, R. T. (2002). Testing a conservation of resources model of the dynamics of emotional labor. Journal of Occupational Health Psychology, 7, 57-67.

Bryk, A. S., \& Raudenbush, S. W. (1992). Hierarchical linear models: Application and data analysis methods. Newbury Park, CA: Sage.

Csikszentmihalyi, M., \& Larson, R. (1987). The experience sampling method. Journal of Nervous and Mental Disease, 175, 526-536.

Csikszentmihalyi, M., \& LeFevre, J. (1989). Optimal experience in work and leisure. Journal of Personality and Social Psychology, 56, $815-822$.

Diefendorff, J. M., \& Richard, E. M. (2003). Antecedents and consequences of emotional display rule perceptions. Journal of Applied Psychology, 88, 284-294.

Diener, E., \& Emmons, R. A. (1984). The independence of positive and negative affect. Journal of Personality and Social Psychology, 47, 1105-1117.

Eid, M., \& Diener, E. (1999). Intraindividual variability in affect: Reliability, validity, and personality correlates. Journal of Personality and Social Psychology, 76, 662-676.

Eysenck, H. J., \& Eysenck, M. W. (1985).
Personality and individual differences: $A$ natural science approach. New York: Plenum Press.

Fisher, C. D. (2000). Mood and emotions while working: Missing pieces of job satisfaction. Journal of Organizational Behavior, 21, 185-202.

Fortson, K. (2004). Diurnal pattern of on-the-job injuries. Monthly Labor Review, 127, 18-25.

Frijda, N. H. (1993). Moods, emotion episodes, and emotions. In Lewis, M., \& Haviland, J. M. (Eds.), Handbook of emotions (pp. 381-403). New York \& London: The Guilford Press.

Fullagar, C. J., \& Kelloway, E. K. (2009). Flow at work: An experience sampling approach. Journal of Occupational and Organizational Psychology, 82, 595-615.

Fuller, J. A., Stanton, J. M., Fisher, G. G., Spitzmüller, C., Russell, S. S., \& Smith, P. C. (2003) A lengthy look at the daily grind: Time series analysis of job stress and satisfaction. 1019-1033.

Goldberg, L. R. (1992). The development of markers for the Big-Five factor structure. Psychological Assessment, 4, 26-42.

Grandey, A. A. (2000). Emotion regulation in the workplace: A new way to conceptualize emotional labor. Journal of Occupational Health Psychology, 5, 59-100.

Grandey, A. A., Fisk, G. M., \& Steiner, D. D. (2005). Must "service with a smile" be stressful? The moderating role of personal control for American and French employees. Journal of Applied Psychology, 90, 893-904.

Gross, J. J. (2002). Emotion regulation: Affective, cognitive, and social consequences. Psychophysiology, 39, 281-291. 
Gross, J. J., Sutton, S. K., \& Ketelaar, T. (1998). Relations between affect and personality: Support for the affect-level and affective reactivity hypotheses. Personality and Social Psychology Bulletin, 24, 279-288.

Ilies, R., \& Judge, T. A. (2002). Understanding the dynamic relationships among personality, mood, and job satisfaction: A field experience sampling study. Organizational Behavior and Human Decision Processes, 89, 1119-1139.

Judge, T. A., Hulin, C. L., \& Dalal, R. S. (in press). Job satisfaction and job affect. In S. W. J. Kozlowski (Ed.), The Oxford handbook of industrial and organizational psychology. New York: Oxford University Press.

Kahneman, D., Krueger, A. B., Schkade, D. A., Schwarz, N., \& Stone, A. A. (2004). A survey method for characterizing daily life experience: The Day Reconstruction Method (DRM). Science, 306, 1776-1780.

Kaplan, S., Bradley, J. C., Luchman, J. N., \& Haynes, D. (2009). On the role of positive and negative affectivity in job performance: A meta-analytic investigation. Journal of Applied Psychology, 94, 162-176.

Kuppens, P., Allen, N. B., \& Sheeber, L. (2010). Emotional inertia and psychological maladjustment. Psychological Science, 21, 984-991.

Larsen, R. J., \& Diener, E. (1992). Promises and problems with the circumplex model of emotions. Review of Personality and Social Psychology, 13, 25-29.

Larsen, R. J., \& Kasimatis, M. (1990). Individual differences in entrainment of mood to the weekly calendar. Journal of Personality and Social Psychology, 58, 164-171.

Larsen, R. J., \& Ketelaar, T. (1991). Personality and susceptibility to positive and negative emotional states. Journal of Personality and Social Psychology, 61, 132-140.

Miner, A. G., Glomb, T. M., \& Hulin, C. (2005) Experience sampling mood and its correlates at work. Journal of Occupational and Organizational Psychology, 78, 171-193.

Moskowitz, D. S., \& Zuroff, D. C. (2004). Flux, Pulse, and Spin: Dynamic additions to the personality lexicon. Journal of Personality and Social Psychology, 86, 880-893.

Muraven, M., \& Baummeister, R. F. (2000) Self-regulation and depletion of limited resources: Does self-control resemble a muscle? Psychological Bulletin, 126, 247-259.

Murray, G., Allen, N. B., \& Trinder, J. (2002). Longitudinal investigation of mood variability and the FFM: Neuroticism predicts variability in extended states of positive and negative affect. Personality and Individual Differences, 33, 1211-1228.

$\mathrm{Ng}$, W. (2009). Clarifying the relation between neuroticism and positive emotions. Personality and Individual Differences, 47, 69-72.

Raudenbush, S. W., \& Bryk, A. S. (2002). Hierarchical linear models (2nd Ed.). Thousand Oaks: Sage Publications.

Raudenbush, S. W., Bryk, A. S., \& Congdon, R. (2004). HLM 6. Lincolnwood, IL: Scientific Software International.

Reid, H. L. (1928). Time of day accidents occur. Industrial Hygiene Bulletin, 5. 
Robinson, M. D., \& Clore, G. L. (2002). Belief and feeling: Evidence for an accessibility model of emotional self-report. Psychological Bulletin, 128, 934-960.

Rothbard, N. P. (2001). Enriching or depleting: The dynamics of engagement in work and family roles. Administrative Science Quarterly, 46, 655-684.

Russell, J. A. (1980). A circumplex model of affect. Journal of Personality and Social Psychology, 39, 1161-1178.

Sheldon, K. M., Ryan, R., \& Reis, H. T. (1996). What makes for a good day? Competence and autonomy in the day and in the person. Personality \& Social Psychology Bulletin, 22, 1270-1279.

Sonnentag, S., \& Frese, M. (2003). Stress in organizations. In W. C. Borman, D. R. Ilgen, \& R. J. Klimoski (Eds.), Handbook of Psychology, volume 12 (pp.453-491). Hoboken: John Wiley.

Sonnentag, S., \& Kruel, U. (2006). Psychological detachment from work during off-job time: The role of job stressors, job involvement, and recovery-related self-efficacy. European Journal of Work and Organizational Psychology, 15, 197-217.

Spector, P. E. (2002). Employee control and occupational stress. Current Directions in Psychological Science, 11, 133-136.

Staw, B. M., Bell, N. E., \& Clausen, J. A. (1986).

The dispositional approach to job attitudes: A lifetime longitudinal test. Administrative Science Quarterly, 31, 57-77.

Stone, A. A., Neale, J., \& Shiffman, S. (1993).
Daily assessment of stress and coping and their association with mood. Annals of Behavioral Medicine, 15, 8-16.

Stone, A. A., Schwartz, J. E., Schwarz, N., Schkade, D., Krueger, A., \& Kahneman, D. (2006). A population approach to the study of emotion: Diurnal rhythms of a working day examined with the Day Reconstruction Method. Emotion, 6, 139-149.

Stone, A. A., Smyth, J. M., Pickering, T., \& Schwartz, J. (1996). Daily mood variability: Form of diurnal patterns and determinants of diurnal patterns. Journal of Applied Social Psychology, 26, 1286-1305.

Suls, J., Green, P., \& Hillis, S. (1998). Emotional reactivity to everyday problems, affective inertia, and neuroticism. Personality and Social Psychology Bulletin, 24, 127-136.

Tan, H. H., Foo, M. D., Chong, C. L., \& Ng, R. (2003). Situational and dispositional predictors of display of positive emotions. Journal of Organizational Behavior, 24, 961 -978.

Thoresen, C. J., Kaplan, S. A., Barsky, A. P., Warren, C. R., \& de Chermont, K. (2003). The affective underpinnings of job perceptions and attitudes: A meta-analytic review and integration. Psychological Bulletin, 129, 914-945.

Wanous, J. P., Reichers, A. E., \& Hudy, M. J. (1997). Overall job satisfaction: How good are single-item measures? Journal of Applied Psychology, 82, 247-252.

Watson, D. (2000). Mood and temperament. New York: Guilford Press.

Watson, D., \& Tellegen, A. (1985). Towards a consensual structure of mood. Psychological 
Bulletin, 98, 219-235.

Weiss, H. M., \& Cropanzano, R. (1996). Affective events theory: A theoretical discussion of the structure, causes, and consequences of affective experiences at work. Research in Organizational Behavior, 18, 1-74.

Weiss, H. M., Nicholas, J. P., \& Daus, C. S. (1999). An examination of the joint effects of affective experiences and job beliefs on job satisfaction and variations in affective experiences over time. Organizational Behavior and Human Decision Processes, 78, 1-24.

Williams, D. G. (1990). Effects of psychoticism, extraversion, and neuroticism in current mood: a statistical review of six studies. Journal of Personality and Individual Differences, 11, 615-630.
Williams, K. J., \& Alliger, G. M. (1994). Role stressors, mood spillover, and perceptions of work-family conflict in employed parents. Academy of Management Journal, 37, 837-868.

Wood, C., \& Magnello, M. E. (1992). Diurnal changes in perceptions of energy and mood. Journal of the Royal Society of Medicine, 85, 191-194.

Wood, C., Magnello, M. E., \& Sharpe, M C. (1992). Fluctuations in perceived energy and mood among patients with chronic fatigue syndrome. Journal of the Royal Society of Medicine, 85, 195-198.

1차 원고접수 : 2013. 01. 07 2차 원고접수 : 2013. 04. 20 최종게재결정 : 2013. 04. 26 


\title{
근로자들의 하루 근무 시간 동안의 정서 역동: 신경증의 조절 효과
}

\author{
장 재 윤 \\ A. L. Cook \\ S. C. Payne \\ 서강대학교 \\ Texas A\&M University
}

\begin{abstract}
본 연구의 목적은 긍정 및 부정 정서가 하루 근무 일 동안에 어떻게 변화하는 지, 그리고 그러한 변화에서의 신경증과 직무만족의 조절 효과를 조사하는 것이었다. 일상재구성법 (DRM)을 사용하여 201 명의 서울 시민으로부터 수집된 자료를 분석하였으며, 분석 결과, 부 정 정서는 하루 중 근무 시간이 지남에 따라 증가하는 형태를 보였으나 긍정 정서는 그러한 형태를 보이지 않았다. 직무만족은 긍정 정서의 평균과는 정적으로 관련되었으나, 부정 정서 와는 부적으로 관련되었으며, 신경증은 그 반대의 관련성을 보였다. 또한 신경증은 부정 정 서의 시간에 따른 변화 형태에 있어 조절 효과를 보였는데, 즉, 고 신경증 근로자들의 부정 정서는 저 신경증 근로자들보다 더 가파르게 증가하는 형태를 보였다. 그러나 예상과는 달 리 직무만족은 긍정 및 부정 정서의 변화 형태에 있어 그러한 조절효과를 보이지 않았다. 본 연구의 결과 중 하루 중 부정 정서의 변화 형태는 최적의 집중 시간이나 효율성, 그리고 안전사고 등의 예방 등의 측면에서 다양한 시사점을 제공한다.
\end{abstract}

주요어 : 정서, 감정, 역동, 신경증, 직무만족, 정서 변산성, 일상재구성법 